\title{
Brachiaria humidicola (Rendle) Schweick EM DIFERENTES IDADES DE REBROTA SUBMETIDA A DOSES DE NITROGÊNIO E POTÁSSIO
}

\author{
Brachiaria humidicola (Rendle) Schweick in different \\ cutting ages under nitrogen and potassium fertilization \\ Bruno Borges Deminicisi ${ }^{1}$ João Batista Rodrigues de Abreu², \\ Henrique Duarte Vieira ${ }^{3}$, Saulo Alberto do Carmo Araújo ${ }^{4}$
}

\begin{abstract}
RESUMO
Avaliou-se o efeito da aplicação de doses de nitrogênio associado ao potássio, em quatro idades de rebrota, sobre o índice de área foliar (IAF), produção de matéria seca (MS), teores de proteína bruta (PB) e fibra em detergente neutro (FDN) e relação folha/ colmo (F/C) de Brachiaria humidicola (Rendle) Schweick. Foram testadas as seguintes doses de nitrogênio (N), na forma de uréia agrícola, e de potássio $\left(\mathrm{K}_{2} \mathrm{O}\right)$, na forma de cloreto de $\mathrm{K}$, em kg/ha/ano: 0 de $\mathrm{N}+100$ de $\mathrm{K}_{2} \mathrm{O} ; 100$ de $\mathrm{N}+100$ de $\mathrm{K}_{2} \mathrm{O} ; 200$ de $\mathrm{N}+200$ de $\mathrm{K}_{2} \mathrm{O}$ e 400 de $\mathrm{N}+400$ de $\mathrm{K}_{2} \mathrm{O}$. As aplicações foram feitas em quantidades equivalentes a $1 / 6$ do total anual (parceladas em 6 vezes), para melhorar a eficiência da fertilização. Os resultados demonstraram efeito significativo para as idades de rebrota e adubação na produção de MS. Não foi observado efeito $(\mathrm{P}>0,05)$ sobre os teores de FDN em resposta aos tratamentos estudados. As variáveis relação F/C, PB e IAF foram influenciadas $(\mathrm{P}<0,05)$ pelas idades de rebrota da gramínea estudada.
\end{abstract}

Termos para indexação: Composição química, produção de MS, relação F/C.

\section{ABSTRACT}

The effect of levels of nitrogen $(\mathrm{N})$ fertilization associated with potassium $\left(\mathrm{K}_{2} \mathrm{O}\right)$ and four growth intervals on the dry matter (DM) production, levels of crude protein (CP) and neutral detergent fiber (NDF), leaf/stem (L/S) ratio and leaf area index (LAI) of Brachiaria humidicola (Rendle) Schweick were studied. The following doses of $\mathrm{N}$ were tested, as agricultural urea, and $\mathrm{K} \mathrm{O}$, as potassium chloride, in $\mathrm{kg} / \mathrm{ha} / \mathrm{year}: 0$ of $\mathrm{N}+100$ of $\mathrm{K}_{2} \mathrm{O} ; 100$ of $\mathrm{N}+100$ of $\mathrm{K}_{2} \mathrm{O} ; 200$ of $\mathrm{N}+200$ of $\mathrm{K}_{2} \mathrm{O}$ and 400 of $\mathrm{N}+400$ of $\mathrm{K}_{2} \mathrm{O}$. The applications were in equivalent amounts of $1 / 6$ of the annual total (in 6 parcels) to improve the efficiency of fertilization. We observed a significant effect of the fertilization levels and cutting ages on DM production. The effect of fertilization rates and growth intervals did not affect the NDF content of the grass $(\mathrm{P}>0.05)$, but $\mathrm{CP}$ content, $\mathrm{LAI}$ and $\mathrm{L} / \mathrm{S}$ ratio were influenced by growth intervals $(\mathrm{P}<0.05)$

Index terms: Chemical composition, DM production, L/S ratio.

(Recebido em 12 de janeiro de 2009 e aprovado em 18 de janeiro de 2010)

\section{INTRODUÇÃO}

No Brasil, as pastagens de gramíneas têm grande importância, sendo a principal fonte de alimento de menor custo para rebanhos leiteiros e de corte. Entre as diversas espécies utilizadas nas pastagens, nos sistemas de produção de ruminantes, o capim-Quicuio-da-Amazônia [Brachiaria humidicola (Rendle) Schweick.] é uma espécie de hábito decumbente, enraizamento rápido e crescimento vigoroso que tem apresentado uma grande expansão no trópico úmido sul-americano, em decorrência de sua alta produtividade em solos ácidos e de baixa fertilidade natural. Apresenta bom comportamento em solos arenosos, tolerância à seca prolongada, suporta inundações breves, possui boa recuperação após a ocorrência de queima, agressividade, resistência ao ataque da cigarrinha-da-pastagem [Notozulia entreriana (Berg., 1879)] e razoável valor nutritivo (Galvão \& Lima, 1982; Camarão et al., 1983; Dias Filho, 1983). Depois de estabelecida, pode atingir alturas de 50 a $80 \mathrm{~cm}$, poporcionando excelente cobertura e proteção do solo, com um rendimento de matéria seca (MS) de até 20 t/ha/ano e teores de até $9 \%$ de proteína bruta (PB) na MS (Tergas, 1983; Anzola, 1990; Skerman \& Riveros, 1992).

O conhecimento da variação da composição química das plantas forrageiras nos diversos estádios fenológicos é um dos fatores a ser considerado para o seu manejo adequado. À medida que as gramíneas tropicais maturam há uma redução nos teores de PB e elevação nos de MS, cinza, celulose e lignina, resultando em decréscimos

\footnotetext{
"Universidade Estadual do Norte Fluminense "Darcy Ribeiro"/UENF - Laboratório de Fitotecnia/LFIT - Avenida Alberto Lamego - 2000 - Parque Califórnia - 28013-600 - Campos dos Goytacazes, RJ - deminicis@uenf.br

Universidade Federal Rural do Rio de Janeiro/UFRRJ - Departamento de Nutrição Animal e Pastagens - Seropédica, RJ

"Universidade Estadual do Norte Fluminense "Darcy Ribeiro"/UENF - Laboratório de Fitotecnia LFIT - Campos dos Goytacazes, RJ

${ }^{4}$ Universidade Estadual do Norte Fluminense "Darcy Ribeiro"/UENF - Laboratório de Zootecnia e Nutrição Animal/LZNA - Campos dos Goytacazes, RJ
} 
da digestibilidade e aceitabilidade da gramínea pelos animais. Cortes ou pastejos menos frequentes resultam em maiores produções de forragem, porém, concomitantemente, ocorrem alterações acentuadas na sua composição química (Costa \& Oliveira, 1994; Costa et al., 1997; Lista et al., 2007). Logo, deve-se procurar o ponto de equilíbrio entre produção e qualidade da forragem, visando a atender os requerimentos nutricionais dos animais $\mathrm{e}$ garantir a persistência e a produtividade das pastagens (Costa \& Oliveira et al., 2005).

Características como altura da planta, relação folha/ colmo (F/C), taxa de crescimento, dinâmica de perfilhamento, remoção de meristemas apicais, expansão foliar, entre outras, apresentam uma relação direta com a produtividade e qualidade da forragem em oferta, além de subsidiarem a adoção de práticas de manejo mais adequadas (Costa \& Paulino et al., 2007). As folhas, como os caules, são os órgãos das plantas forrageiras que exibem decréscimo no valor nutritivo com a maturidade e apresentam maior concentração de nutrientes digestíveis na MS (Pedreira \& Boin, 1969; Silveira, citado por Abreu et al., 2004). Uma vez que a emissão de folhas não pode ser significativamente alterada (Langer, 1972) e que a porcentagem de colmo tende a aumentar antes do florescimento, torna-se necessário manter vivo o maior número de folhas na planta para obter, por mais tempo, uma boa relação F/C.

O índice de área foliar (IAF) é um índice dinâmico, visto que, a área foliar que ocupa uma determinada superfície de solo varia quase que instantaneamente ao longo do ciclo da planta, o que torna sua quantificação bastante complexa. Assim, os valores de IAF encontrados na literatura referem-se a estimativas pontuais da área foliar num determinado estádio de desenvolvimento (Machado et al., 2007). Em termos fisiológicos, a produção de forragem é limitada pela quantidade de luz interceptada pelo dossel (dependente da área foliar e dos padrões de interceptação de luz), pela eficiência desse dossel na conversão da energia luminosa em massa seca e pela presença de limitações quantitativas de água e nutrientes.

O objetivo da condução desse trabalho foi avaliar a produção de MS, os teores de PB e fibra em detergente neutro (FDN), a relação F/C e o IAF do capim-quicuio-daAmazônia (Brachiaria humidicola), em diferentes idades de rebrota submetido a doses de nitrogênio $(\mathrm{N})$ e potássio $\left(\mathrm{K}_{2} \mathrm{O}\right)$, a fim de se maximizar o seu uso em sistemas de pastejo.

\section{MATERIAL E MÉTODOS}

Conduziu-se o experimento em parcelas demarcadas em pastagem de Brachiaria humidicola implantada a aproximadamente 15 anos, no Setor de Caprinocultura do
Instituto de Zootecnia da Universidade Federal Rural do Rio de Janeiro, no período de 09 de dezembro de 2002 a 04 de fevereiro de 2003. A topografia da área é plana e o clima é do tipo AW, da classificação de Köppen (Ometto, 1981), apresentando duas estações distintas, uma seca que se estende de abril a setembro e outra quente e chuvosa que se estende de outubro a março. Levantamentos dos últimos dez anos, segundo informações da Estação Meteorológica da PESAGRO-RIO, mostraram que a precipitação média anual foi de $1217 \mathrm{~mm}$, com as maiores precipitações ocorrendo, normalmente, no período de verão-outono, concentrandose entre dezembro $(172 \mathrm{~mm})$, janeiro $(187 \mathrm{~mm})$ e fevereiro (162 mm), o que correspondeu a $42 \%$ da chuva total anual. As temperaturas médias anuais máximas e mínimas foram, respectivamente, iguais a $29,8^{\circ} \mathrm{C}$ e $20,1^{\circ} \mathrm{C}$.

O solo da pastagem antes do início do experimento apresentava a seguinte característica, na camada de 0 a $20 \mathrm{~cm}$ : $\mathrm{pH}=6,0 ; \mathrm{Al}=0,0 \mathrm{cmolc} / \mathrm{dm}^{3} ; \mathrm{Ca}=2,0 \mathrm{cmolc} / \mathrm{dm}^{3} ; \mathrm{Mg}=1,5$ cmolc/ $/ \mathrm{dm}^{3} ; \mathrm{P}=10 \mathrm{mg} / \mathrm{dm}^{3} ; \mathrm{K}=47 \mathrm{mg} / \mathrm{dm}^{3}$ e matéria orgânica = $1,34 \%$.

O delineamento experimental utilizado foi o de blocos ao acaso, com o arranjo fatorial de $4 \times 4$ (quatro doses de $\mathrm{Ne}_{2} \mathrm{O}$ e quatro idades de rebrota), em quatro repetições, totalizando 64 parcelas. As unidades experimentais foram constituídas por parcelas de $2 \times 2 \mathrm{~m}$, com área útil de $1 \mathrm{~m}^{2}$.

Foram testadas as seguintes doses de nitrogênio $(\mathrm{N})$, na forma de uréia agrícola, e de potássio $\left(\mathrm{K}_{2} \mathrm{O}\right)$, na forma de cloreto de $\mathrm{K}$, em $\mathrm{kg} / \mathrm{ha} / \mathrm{ano}: 0 \mathrm{de} \mathrm{N}+100$ de $\mathrm{K}_{2} \mathrm{O}$; 100 de $\mathrm{N}+100$ de $\mathrm{K}_{2} \mathrm{O} ; 200$ de $\mathrm{N}+200$ de $\mathrm{K}_{2} \mathrm{O}$ e 400 de $\mathrm{N}+$ 400 de $\mathrm{K}_{2} \mathrm{O}$. As aplicações foram feitas em quantidades equivalentes a $1 / 6$ do total anual (parceladas em 6 vezes), para melhorar a eficiência da fertilização.

Foi realizado o corte com roçadeira mecânica, rente ao solo, para a uniformização da gramínea, nas datas de 09 e 10/12/2002; 23 e 24/12/2002; 06 e 07/01/2003 e 20 e 21/01/2003, que correspondem, respectivamente, aos intervalos de crescimento de 56, 42, 28 e 14 dias (8, 6, 4 e 2 semanas). Todo o material para as análises foi coletado em 03 e 04/02/2003, respectivamente, nos blocos 1 e 2,3 e 4 .

Os cortes para estimativa de produção da forragem foram feitos na área útil $\left(1 \mathrm{~m}^{2}\right)$ de cada parcela, procedendose o corte a uma altura de $10 \mathrm{~cm}$ do solo e toda a massa colhida foi pesada. Da forragem verde colhida para determinação da produção de MS, foram retiradas subamostras, de aproximadamente $300 \mathrm{~g}$, para determinação do teor de MS, da relação F/C, do IAF e dos teores de MS, $\mathrm{PB}$ e FDN.

$\mathrm{O}$ material relativo à relação $\mathrm{F} / \mathrm{C}$ foi separado em folha e colmo + bainha, pesado e colocado separadamente em sacos de papel, os quais foram encaminhados 
diretamente para estufa de circulação forçada a $55^{\circ} \mathrm{C}$ por 72 horas. Posteriormente, as amostras foram pesadas e processadas em moinho com peneiras de crivos de $1 \mathrm{~mm}$ e acondicionadas em recipiente hermeticamente fechado. $\mathrm{O}$ mesmo procedimento foi adotado para as análises da planta inteira. As determinações dos teores de MS e PB foram realizadas segundo técnicas descritas por Silva \& Queiroz (2002), enquanto para a dos teores de FDN foi utilizado o método descrito por Soest \& Robertson (1985). Para a determinação do IAF foi utilizado o programa computacional para análise de imagens Delta-T Scan. Os dados obtidos referentes às produções de MS, à relação $\mathrm{F} / \mathrm{C}$, ao IAF e aos teores de $\mathrm{PB}$ e FDN foram submetidos à análise de variância pelo Sistema de Análises Estatísticas Sisvar (Ferreira, 2002) e ao teste de Tukey, admitindo-se valores inferiores a $5 \%$ de probabilidade, para verificar diferenças entre os intervalos de rebrota e as doses de $\mathrm{Ne}$ $\mathrm{K}_{2} \mathrm{O}$. Quando pertinente, procedeu-se a análise de regressão, com nível de significância de $5 \%$.

\section{RESULTADOS E DISCUSSÃO}

Foram detectados efeitos significativos $(\mathrm{P}<0,05)$ da idade de rebrota e adubação e da interação desses fatores sobre a produção de MS. O desdobramento do efeito de doses de $\mathrm{N}$ e $\mathrm{K}_{2} \mathrm{O}$ dentro de cada intervalo de rebrota, por meio da análise de regressão, mostrou um ajuste ao modelo linear para os intervalos de 28, 42 e 56 dias (Figura 1). Isso demonstra o elevado potencial responsivo dessa forrageira às aplicações desses nutrientes.
Entretanto, não houve ajuste dos valores de produção de MS observados para 14 dias de crescimento às curvas de $1^{\mathrm{a}} \mathrm{e} 2^{\mathrm{a}}$ ordem. Houve um aumento da produção de MS da menor para a maior dose, contudo, o maior coeficiente de regressão foi aos 56 dias, superior ao de 42 e este, por sua vez, maior que o de 28 dias. Isso demonstra que há uma maior produção de MS à medida que se aumenta o intervalo de corte e as doses de $\mathrm{N}_{\text {e }} \mathrm{K}_{2} \mathrm{O}$. Contudo, como só foi feito um corte, a resposta da produção aos 42 e 56 dias pode ser decorrente do maior tempo de assimilação do N.

Contudo, os valores obtidos para a produção de MS no intervalo de 56 dias com $0 \mathrm{~kg}$ de $\mathrm{N}+100 \mathrm{~kg}$ de $\mathrm{K}_{2} \mathrm{O}$ não foram semelhantes aos obtidos por Reis \& Azambuja, citados por Abreu et al. (2004) que foi de 10 t/ha de MS apesar desses autores não terem aplicado $\mathrm{N}_{\mathrm{e}} \mathrm{K}_{2} \mathrm{O}$ no mesmo intervalo. No geral, a adubação com $400 \mathrm{~kg}$ de $\mathrm{N}+400 \mathrm{~kg}$ de $\mathrm{K}_{2} \mathrm{O}$ aumentou em $191 \%$ a produção de MS em comparação ao tratamento com $0 \mathrm{~kg}$ de $\mathrm{N}+100 \mathrm{~kg}$ de $\mathrm{K}_{2} \mathrm{O}$, sendo que, no intervalo de 56 dias o tratamento com $400 \mathrm{~kg}$ de $\mathrm{N}+400 \mathrm{~kg}$ de $\mathrm{K}_{2} \mathrm{O}$ aumentou em $335 \%$ a produção de $\mathrm{MS}$ em comparação ao tratamento com $0 \mathrm{~kg}$ de $\mathrm{N}+100 \mathrm{~kg}$ de $\mathrm{K}_{2} \mathrm{O}$.

Os valores de relação F/C (Figura 2 e Tabela 1) apresentaram diferenças significativas $(\mathrm{P}<0,05)$ apenas entre as idades de rebrota. Na menor idade, observa-se baixa relação F/C em razão do curto período de formação de folhas, que teve valores da relação $\mathrm{F} / \mathrm{C}$ aumentados até 28 dias, momento em que se observou o início do surgimento das inflorescências, acarretando redução da relação $\mathrm{F} / \mathrm{C}$ nas idades posteriores.

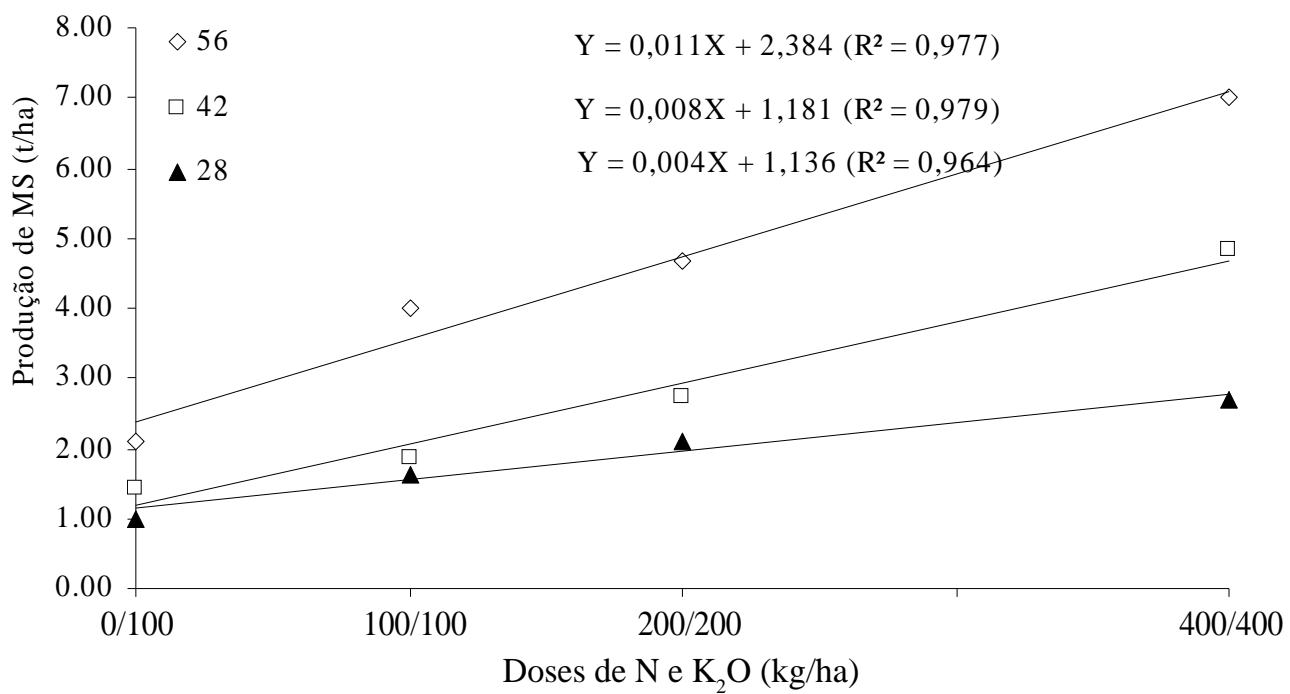

Figura 1 - Produção total de MS de Brachiaria humidicola em função de doses de $\mathrm{N} \mathrm{K}_{2} \mathrm{O}$ nos intervalos de rebrota de 28,42 e 56 dias. 


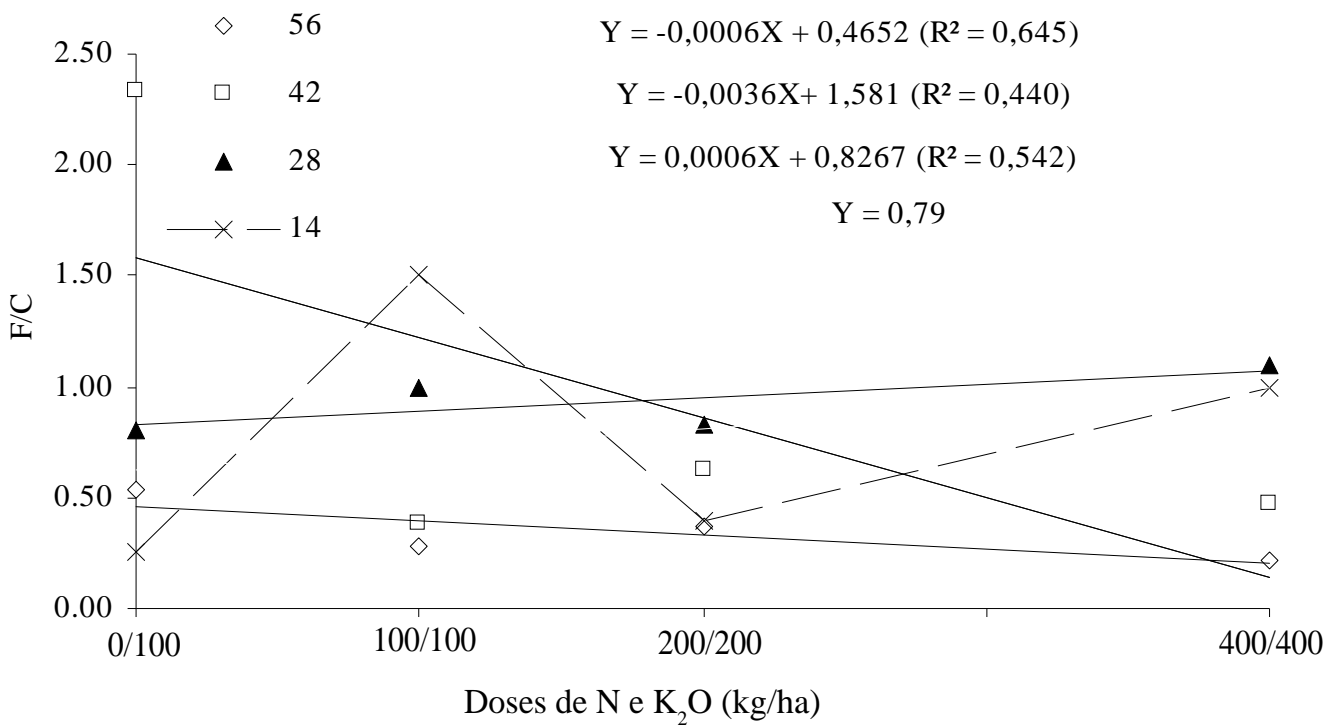

Figura 2 - Valores de relação folha/colmo (F/C), de Brachiaria humidicola em função de doses de $\mathrm{N}_{\text {e }} \mathrm{K}_{2} \mathrm{O}$ nos intervalos de rebrota de 14, 28, 42 e 56 dias.

Tabela 1 - Relação folha/colmo (F/C), teores (\% na MS) de fibra em detergente neutro (FDN) e de proteína bruta (PB) e índice de área foliar (IAF, $\mathrm{m}^{2}$ de área foliar $/ \mathrm{m}^{2}$ de área utilizada) de Brachiaria humidicola em função de doses de $\mathrm{N}$ e $\mathrm{K}_{2} \mathrm{O}$ e intervalos de rebrota.

\begin{tabular}{|c|c|c|c|c|c|c|}
\hline & \multicolumn{2}{|c|}{ Doses $(\mathrm{kg} / \mathrm{ha})$} & \multicolumn{4}{|c|}{ Idades de rebrota (dias) } \\
\hline & $\mathrm{N}$ & $\mathrm{K}_{2} \mathrm{O}$ & 14 & 28 & 42 & 56 \\
\hline \multirow[t]{4}{*}{$\mathrm{F} / \mathrm{C}$} & 0 & 100 & $0,37 \mathrm{Ab}$ & $0,73 \mathrm{Aab}$ & $1,09 \mathrm{Aa}$ & $0,48 \mathrm{Ab}$ \\
\hline & 100 & 100 & $0,70 \mathrm{Aa}$ & $0,97 \mathrm{Aa}$ & $0,62 \mathrm{Aa}$ & $0,44 \mathrm{Aa}$ \\
\hline & 200 & 200 & $0,47 \mathrm{Aa}$ & $0,62 \mathrm{Aa}$ & $0,63 \mathrm{Aa}$ & $0,35 \mathrm{Aa}$ \\
\hline & 400 & 400 & 0,49 Aab & $1,07 \mathrm{Aa}$ & 0,60 Aab & $0,30 \mathrm{Ab}$ \\
\hline \multirow[t]{4}{*}{ FDN } & 0 & 100 & $76,52 \mathrm{Aa}$ & $74,67 \mathrm{Aa}$ & $69,14 \mathrm{Aa}$ & $68,80 \mathrm{Aa}$ \\
\hline & 100 & 100 & $69,66 \mathrm{Aa}$ & $74,82 \mathrm{Aa}$ & $74,65 \mathrm{Aa}$ & $70,75 \mathrm{Aa}$ \\
\hline & 200 & 200 & 76,32 Аа & $67,05 \mathrm{Aa}$ & $73,57 \mathrm{Aa}$ & $66,21 \mathrm{Aa}$ \\
\hline & 400 & 400 & $78,06 \mathrm{Aa}$ & $76,92 \mathrm{Aa}$ & $69,66 \mathrm{Aa}$ & $70,28 \mathrm{Aa}$ \\
\hline \multirow[t]{4}{*}{ PB } & 0 & 100 & 6,38 Aa & $6,62 \mathrm{Aa}$ & $6,57 \mathrm{Aa}$ & $5,93 \mathrm{Aa}$ \\
\hline & 100 & 100 & 6,39 Aa & 6,61 Aa & $6,51 \mathrm{Aa}$ & 5,04 Aa \\
\hline & 200 & 200 & $6,60 \mathrm{Aa}$ & 6,79 Aa & $5,66 \mathrm{Aa}$ & $5,22 \mathrm{Aa}$ \\
\hline & 400 & 400 & $6,18 \mathrm{Ab}$ & $8,37 \mathrm{Aa}$ & $6,71 \mathrm{Aab}$ & $5,41 \mathrm{Ab}$ \\
\hline \multirow[t]{4}{*}{ IAF } & 0 & 100 & $0,87 \mathrm{Ad}$ & $1,84 \mathrm{Ac}$ & $2,82 \mathrm{Ab}$ & $3,06 \mathrm{Aa}$ \\
\hline & 100 & 100 & $0,87 \mathrm{Ad}$ & $1,83 \mathrm{Ac}$ & $2,87 \mathrm{Ab}$ & 3,08 Aa \\
\hline & 200 & 200 & $0,89 \mathrm{Ad}$ & $1,88 \mathrm{Ac}$ & $2,92 \mathrm{Ab}$ & 3,36 Aa \\
\hline & 400 & 400 & $1,01 \mathrm{Ad}$ & $1,89 \mathrm{Ac}$ & $2,95 \mathrm{Ab}$ & 3,39 Aa \\
\hline
\end{tabular}

* Medias seguidas da mesma letra maiúscula na coluna e minúscula na linha, para a mesma variável estudada, não diferem entre si pelo teste de Tukey a $5 \%$. 
Costa et al. (2007) constataram que, para Brachiaria brizantha entre 15 e 20 dias de rebrota, ocorreu maior relação F/C do que entre 30 e 60 dias.

Abreu et al. (2004), estudando Brachiaria humidicola, observaram que o parcelamento da adubação nitrogenada, em três doses, elevou a relação $\mathrm{F} / \mathrm{C}$, cujos valores foram 0,$42 ; 0,43 ; 0,49$ e 0,60 , respectivamente, para zero, 100,200 e $400 \mathrm{~kg} / \mathrm{ha}$ de N. Pinto et al. (1994) verificaram para o capim-Guiné (Panicum maximum Jacq.) diminuição na relação F/C à medida que a idade de rebrota aumentou de 14 para 56 dias com as relações de 1,3 e 0,7 , respectivamente. Balsalobre et al. (2003) argumentaram que as maiores mudanças que ocorrem na composição das plantas forrageiras são aquelas decorrentes de sua maturidade.

As espécies forrageiras sofrem declínio no seu valor nutritivo com o aumento da idade, resultando da menor relação F/C combinada com a crescente lignificação da parede celular.

Quanto ao teor de FDN, não houve efeito $(\mathrm{P}>0,05)$ dos intervalos de crescimento e das doses de $\mathrm{N}$ e $\mathrm{K}_{2} \mathrm{O}$ (Tabela 1 e Figura 3 ). Os valores obtidos no presente trabalho não corroboraram com os descritos por Couto, citado por Abreu et al. (2004), que registrou aumento nos teores de FDN e, consequentemente, decréscimo na qualidade da forragem com o aumento nos intervalos de corte em razão do sombreamento das folhas inferiores que ocasiona morte destas e decréscimos na produção a partir dos 42 a 46 dias.
Os valores observados por Camarão, citado por Souza Junior et al. (2009) foram semelhantes aos verificados no presente estudo, quando determinaram os teores dos constituintes da parede celular de Brachiaria humidicola, em três idades de corte, e obtiveram 72,5; 74,3 e 76,4\% de FDN, respectivamente, para cortes com 35, 65 e 95 dias de rebrota.

Houve efeito do intervalo de rebrota $(\mathrm{P}<0,05)$ sobre os teores de $\mathrm{PB}$ apenas para as doses mais altas de $\mathrm{N}$ e $\mathrm{K}_{2} \mathrm{O}$, sendo encontrado valor de $8,37 \%$ de $\mathrm{PB}$ para 28 dias de rebrota (Tabela 1 e Figura 4).

Esse valor é semelhante ao observado em Rondônia por Gonçalves (1985) que encontrou 8,2\% de $\mathrm{PB}$ apenas nas doses mais elevadas de $\mathrm{N}$ e $\mathrm{K}_{2} \mathrm{O}$, para plantas de Brachiaria humidicola com 35 dias de rebrota. No Amazonas, Italiano \& Silva, citados por Rodrigues et al. (2006) encontraram 8,1 e 6,3\% de PB, respectivamente, para plantas da mesma gramínea com 14 e 56 dias de crescimento. Os valores relativamente constantes com o aumento da disponibilidade de $\mathrm{N}$ podem ser explicados pelo efeito de diluição do elemento, promovendo uma aceleração do crescimento, associado ao baixo potencial genético da planta em elevar os teores de PB, ou seja, converter N em PB, o que caracteriza seu menor valor nutricional. Esse efeito pode ser observado quando a taxa de produção de MS é superior à taxa de absorção relativa do nutriente (Maia et al., 2005).

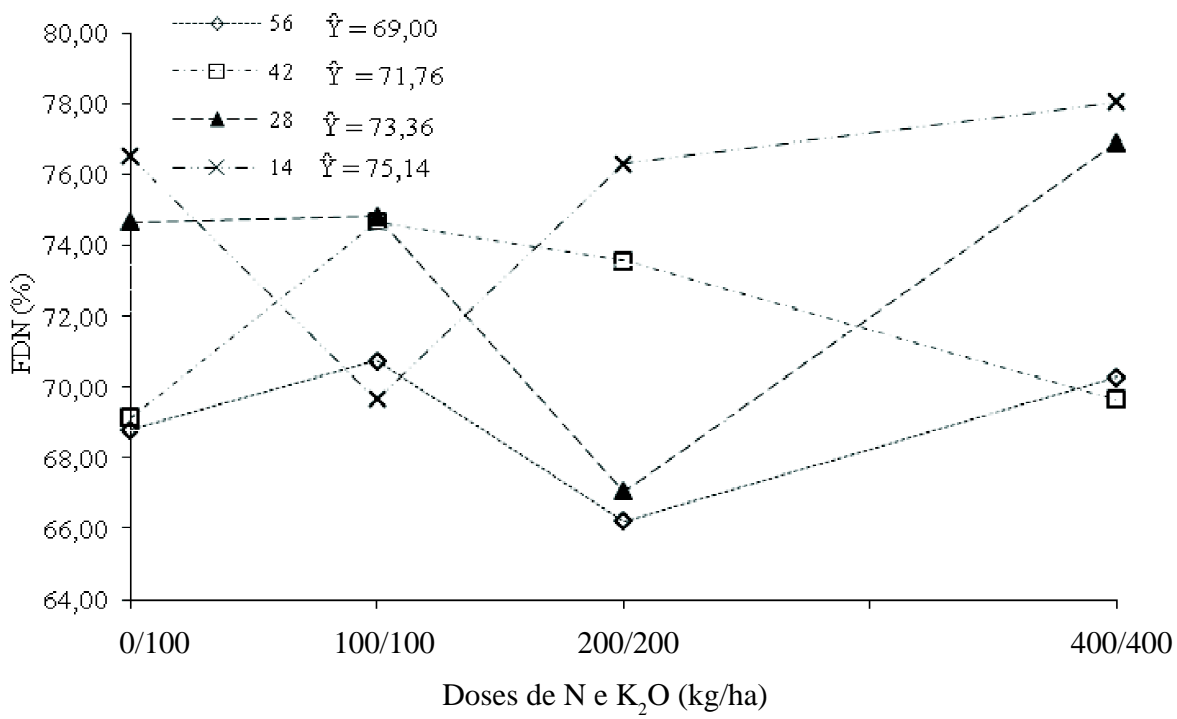

Figura 3 - Teores de fibra em detergente neutro (FDN) na MS de Brachiaria humidicola em função de doses $\mathrm{N}^{\text {e }} \mathrm{K}_{2} \mathrm{O}$ nos intervalos de rebrota de $14,28,42$ e 56 dias. 
O IAF foi diretamente proporcional à idade da planta, sendo os maiores valores obtidos com corte aos 56 dias de rebrota (Tabela1 e Figura 5). Tendências semelhantes foram reportadas por Rodrigues et al. (2006), com várias cultivares de Cynodon, e por Costa et al. (2007), com Brachiaria brizantha Stapf.

Os valores de IAF, neste estudo, foram superiores aos relatados por Berroterán (1989) para Andropogon gayanus Kunth colhido em idades de rebrota semelhantes às utilizadas neste trabalho. Os valores de
IAF obtidos para os intervalos de 14, 28 e 42 dias foram semelhantes aos verificados por Costa \& Paulino (2005), utilizando diferentes genótipos de Brachiaria humidicola submetidos a diferentes idades de rebrota. Foi verificada correlação positiva significativa $(r=0,64)$ entre o IAF e as produções de MS, observação semelhante às reportadas por Costa et al. (2007) que avaliaram Brachiaria brizantha e por Leme et al. (1984) e Oliveira et al. (2007) que trabalharam com Saccharum officinarum L.

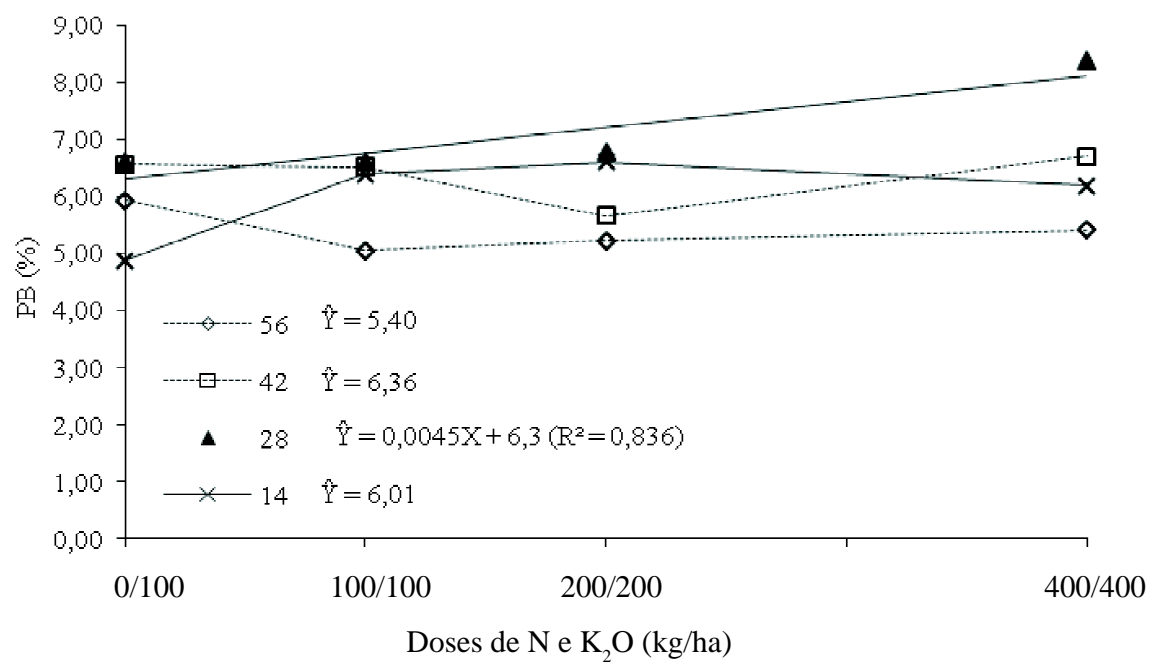

Figura 4 - Teores de proteína bruta (PB), na MS de Brachiaria humidicola em função de doses de $\mathrm{N}_{\text {e }} \mathrm{K}_{2} \mathrm{O}$ nos intervalos de rebrota de $14,28,42$ e 56 dias.

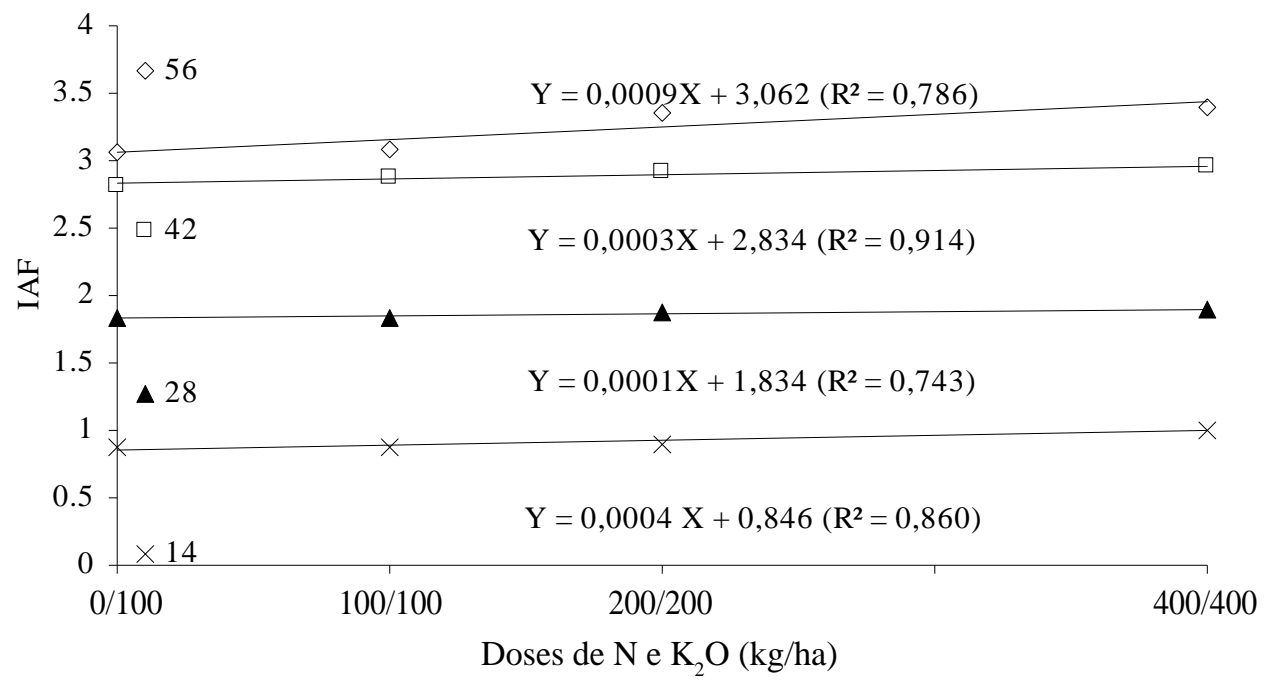

Figura 5 - Valores de índice de área foliar (IAF) de Brachiaria humidicola em função de doses de $\mathrm{N}_{\text {e }} \mathrm{K}_{2} \mathrm{O}$ nos intervalos de rebrota de 14, 28, 42 e 56 dias. 


\section{CONCLUSÕES}

As variáveis índice de área foliar (IAF), relação folha/colmo (F/C) e proteína bruta (PB) não foram influenciadas pelas doses de $\mathrm{N}$ e $\mathrm{K}_{2} \mathrm{O}$ estudadas, porém houve efeito significativo para as idades de rebrota. $\mathrm{O}$ aumento da idade das plantas, associado à maior disponibilidade de nutrientes, resultou em maiores rendimentos de forragem sem, contudo, provocar alterações nos teores de FDN.

\section{REFERÊNCIAS BIBLIOGRÁFICAS}

ABREU, J.B.R.; CÓSER, A.C.; DEMINICIS, B.B.; BRUM, R.P.; SANT'ANA, N.F.; TEIXEIRA, M.C.; SANTOS, A.M.

Avaliação da produção de matéria seca, relação folha/colmo e composição químico-bromatológica de Brachiaria humidicola (rendle), submetida à diferentes idades de rebrota e doses de nitrogênio e potássio. Revista da Universidade Rural, Seropédica, v.24, n.1, p.135-141, 2004.

ANZOLA, L. Siembra de gramíneas y leguminosas. Caracas: Índice Agropecuario, 1990. 11 p.

BALSALOBRE, M.A.A.; CORSI, M.; SANTOS, P.M. Composição química e fracionamento do nitrogênio e dos carboidratos do capim-tanzânia irrigado sob três níveis de resíduo pós-pastejo. Revista Brasileira de Zootecnia, Viçosa, v.32, p.519-528, 2003.

BERROTERÁN, J.L. Respuesta de Andropogon gayanus y Digitaria swazilandensis a la fertilización en los Llanos Centrales de Venezuela. Pasturas Tropicales, Cali, v.11, n.2, p.2-7, 1989.

CAMARÃO, A.P.; AZEVEDO, G.P.C. de; SERRÃO, E.A.S. Produção de matéria seca de novos germoplasmas forrageiros em quatro idades de cortes em São João do Araguaia, PA. Belém: Embrapa-CPATU, 1983. 5p. (Comunicado técnico, 49).

COSTA, K.A. de P.; OLIVEIRA, I.P.; FAQUIN, V.; NEVES, B.P.; RODRIGUES, C.; SAMPAIO, F.M.T. Intervalo de corte na produção de massa seca e composição químico-bromatológica da Brachiaria brizantha cv. MG-5. Ciência e Agrotecnologia, Lavras, v.31, n.4, p.1197-1202, 2007.

COSTA, K.A. de P.; ROSA, B.; OLIVEIRA, I.P. de; CUSTÓDIO, D.P.; SILVA, D.C. e. Efeito da estacionalidade na produção de matéria seca e composição bromatológica da Brachiaria brizantha cv. Marandu. Ciência Animal Brasileira, Goiânia, v.6, n.3, p.187-193, jul./set. 2005.

COSTA, N. de L.; OLIVEIRA, J.R. da C. Evaluación agronômica de accesiones de Panicum maximum em Rondônia. Pasturas Tropicales, Cali, v.16, n.2, p.44-46, 1994.

COSTA, N. de L.; PAULINO, V.T.; TOWNSEND, C.R.; MAGALHÃES, J.A.; OLIVEIRA, J.R.C. Desempenho agronômico de genótipos de Brachiaria brizantha em diferentes idades de corte em Porto Velho, Rondônia, Brasil. Revista Electrónica de Veterinaria, Málaga, v.8, n.8, p.1-5, 2007.

COSTA, N. de L.; TOWNSEND, C.R.; MAGALHÃES, J.A.; PEREIRA, R.G. de A. Resposta de pastagens degradadas de Brachiaria brizantha cv. Marandu à fontes e doses de fósforo. Porto Velho: Embrapa-CPAF, 1997. 4p. (Embrapa-CPAF Rondônia. Comunicado técnico, 138).

DIAS FILHO, M.B. Limitações e potencial de Brachiaria humidicola para o trópico úmido brasileiro. Belém: Embrapa-CPATU, 1983. 28p. (Embrapa-CPATU. Documentos, 20).

FERREIRA, D.F. SISVAR Sistemas de análises de variância para dados balanceados: programa de análises estatísticas e planejamento de experimentos. Versão 4.3. Lavras: UFLA, 2002. CD-ROM.

GALVÃO, F.E.; LIMA, A.F. Capim quicuio-da-amazônia (Brachiaria humidicola) e suas perspectivas no Estado de Goiás. Goiânia: EMGOPA, 1982. 27p. (Circular técnica, 5).

GONÇALVES, C.A. Crescimento e composição química das gramíneas Brachiaria humidicola, Andropogon gayanus cv. Planaltina e Setaria sphacelata cv. Nandi em Porto Velho-RO. Porto Velho: Embrapa-UEPAE, 1985. 23p. (Boletim de pesquisa, 4).

LANGER, R.H.M. How grasses grow. London: E.Arnold, 1972. 60p. (Studies in Biology, 34).

LEME, E.J.A.; MANIER, M.A.; GUIDOLIN, J.C.

Estimativa da área foliar da cana-de-açúcar e sua relação com a produtividade. Cadernos Planalsucar, Piracicaba, v.2, p.3-22. 1984. 
LISTA, F.N.; SILVA, J.F.C. da; VAZQUEZ, H.M.; DETMANN, E.; DOMINGUES, F.N.; FEROLLA, F.S. Avaliação nutricional de pastagens de capim-elefante e capim-mombaça sob manejo rotacionado em função do período de ocupação. Revista Brasileira de Zootecnia, Viçosa, v.36, n.5, p.1413-1418, 2007.

MACHADO, L.A.Z.; FABRICIO, A.C.; ASSIS, P.G.G.; MARASCHIN, G.E. Estrutura do dossel em pastagens de capim-marandu submetidas a quatro ofertas de lâminas foliares. Pesquisa Agropecuária Brasileira, Brasília, v.42, n.10, p.1495-1501, 2007.

MAIA, C.E.; MORAIS, E.R.C.; PORTO FILHO, F.Q.; GUEYI, H.R.; MEDEIROS, J.F. Teores foliares de nutrientes em meloeiro irrigado com águas de diferentes salinidades Revista Brasileira de Engenharia Agrícola e Ambiental, Campina Grande, v.9, p.292-295, 2005. Suplemento.

OMETTO, J.C. Bioclimatologia vegetal. São Paulo: Agronômica Ceres, 1981. 440p.

PEDREIRA, J.V.; BOIN, C. Estudo do crescimento do capim elefante, variedade napier (Pennisetum purpureum, Schum.). Boletim da Indústria Animal, Nova Odessa, v.6, p.263-273, 1969.

PINTO, J.C.; GOMIDE, J.A.; MAESTRI, M. Produção de matéria seca e relação folha/caule de gramíneas forrageiras tropicais, cultivadas em vasos, com duas doses de nitrogênio. Revista Brasileira de Zootecnia, Viçosa, v.23, n.3, p.313-326, 1994.

RODRIGUES, B.H.N.; MAGALHÃES, J.A.; CAVALCANTE, R.F.; BARROS, W.S. Efeito da idade de corte sobre o rendimento forrageiro do capimtanzânia irrigado nos tabuleiros litorâneos do Piauí. Revista Científica de Produção Animal, v.8, n.2, p.21217, 2006.

RODRIGUES, L.R. de A.; RODRIGUES, T. de J.D.; REIS, R.A.; SOARES FILHO, C.V. Avaliação de características fisiológicas de cinco cultivares de Cynodon. Acta

Scientiarum Animal Science, Maringá, v.28, n.3, p.245250, 2006.

SILVA, D.J.; QUEIROZ, A.C. Análise de alimentos: métodos químicos e biológicos. 3.ed. Viçosa, MG: UFV, 2002. 235p.

SKERMAN, P.; RIVEROS, F. Gramíneas tropicales. Rome: FAO, 1992. 232p. (Colección FAO. Producción y Protección Vegetal, 2).

SOEST, P.J. van; ROBERTSON, J.B. Analysis of forage and fibrous foods. Ithaca: Cornell University, 1985. 202p. (Manual for Animal Science, 613).

SOUZA JUNIOR, L.; LOURENÇO JÚNIOR, J.B.; SANTOS, N.F.A.; GONÇALVES, G.F.D.; NAHUM, B.S.; MONTEIRO, E.M.M.; ARAÚJO, C.V.; FATURI, C. Avaliação do valor nutritivo da torta de coco (Cocos nucifera 1.) para suplementação alimentar de ruminantes na amazônia oriental. Amazônia:

Ciência \& Desenvolvimento, Belém, v.4, n.8, p.6381, 2009.

TERGAS, L. El potencial de Brachiaria humidicola para suelos ácidos e infértiles en América Tropical.

Resúmenes Analíticos sobre Pastos Tropicales, Cali, v.5, n.2, p.18-19, 1983. 